\title{
Jóvenes, violencia y pandillas en las periferias de Cartagena-Colombia Aproximaciones teóricas y fragmentos etnográficos
}

\section{Youth, violence and gangs in the outskirts of Cartagena-Colombia Theoretical Approaches and Ethnographic Fragments}

\author{
William Álvarez ${ }^{1}$ \\ williamlogia@gmail.com
}

\begin{abstract}
Resumen
El presente texto hace parte de un avance de mi trabajo de campo hecho en un barrio periférico de la ciudad de Cartagena, reconocido por tener un alto grado de violencia y enfrentamientos entre pandillas conformadas por jóvenes afrodescendientes. El objetivo de este trabajo, es utilizar los datos de esta investigación de campo para pensar un abordaje teórico que comprenda y explique la emergencia reciente de estas pandillas, el uso y formas de este tipo de violencia en el Caribe, en contraste de la interpretación que se tiene sobre la violencia urbana existente en el resto del país asociada al crimen organizado ligado al narcotráfico. Metodológicamente hago uso de la etnografía y la observación participante para tener datos de primera fuente.
\end{abstract}

\section{Palabras clave}

Etnografía, pandillas, barrio, violencia, Cívica.

Forma sugerida de citar: William Álvarez (2016). Jóvenes, violencia y pandillas en las periferias de Cartagena-Colombia. Aproximaciones teóricas y fragmentos etnográficos. Universitas, XIV(25), pp. 191-213.

1 Graduado en Sociología por la Universidad del Atlántico (Colombia), Maestría en Antropología FLACSO-Quito (Ecuador). Candidato a doctorar en Sociología por la Universidad Federal de São Carlos (UFSCAR)/ São Paulo (Brasil). Integrante del grupo de investigación NaMargem: Núcleo de Pesquisas Urbanas (CEBRAP-CEM/UFSCAR). 


\begin{abstract}
This text is part of an advance on my fieldwork done in a suburb of the city of Cartagena (Colombia), recognized as having a high degree of violence and confrontations between gangs formed by young African descent. The aim of this paper is use the data from this field research to think a theoretical approach to understand and explain the recent emergence of these gangs and violence, their forms and use of this kind of violence in Caribean Colombia, totally different from organized crime associate with drug trafficking in the rest of the country. Methodologically I use ethnography and participant observation to have firsthand information.
\end{abstract}

\title{
Keywords
}

Ethnography, gangs, neighborhood, violence, Cívica.

\section{Introducción}

El texto que presento es una propuesta de abordaje teórico-conceptual que se desprende de una investigación mucho más amplia y que tiene como finalidad reflexionar epistemológicamente sobre un problema de violencia urbana que considero está fuera de cualquier interpretación sobre violencia urbana hecha en Colombia. Partiendo de una intensa etnografía y observación participante realizada en el sector Rafael Núñez (en adelante La Villa) del barrio Olaya Herrera $(\mathrm{OH})$ de la ciudad de Cartagena-Colombia con jóvenes pandilleros afrodescendientes. Esta etnografía hace parte de una primera etapa de trabajo de campo y tuvo una duración de tres meses. El objetivo principal del levantamiento de datos fue: 1) conocer espacial y socialmente el lugar de investigación (sector, barrio), 2) crear redes sociales e interlocutores claves para las siguientes etapas de observación.

La etnografía se hizo por etapas, la primera a finales de 2013 para conocer el lugar y analizar la viabilidad del proyecto y mi seguridad personal, la segunda etapa para inicios del 2015 con una intensidad de tres meses, y desde el mes de septiembre del presente año continuó con la tercera etapa profundizando el conocimiento conseguido anteriormente, siguiendo de cerca la cotidia- 
nidad de algunos interlocutores, registrando su vida diaria, lugares de trabajo, habitad, tiempo de ocio y espacios de sociabilidad. La última etapa finalizó en enero 2016, después de 20 días de haber estado residiendo en La Villa.

Mi etnografía se ha enfocado principalmente en registrar las formas de violencia y socializaciones violentas que recientemente se han venido manifestando en la ciudad a través de un número indefinido de pandillas que se ubican principalmente en barrios periféricos de la ciudad como sucede $\mathrm{OH}$. He decidido delimitar mi campo de acción en el sector de La Villa, debido al extenso tamaño del barrio, concentrándome en un área socio-urbana con una larga trayectoria de violencia, robos y criminalidad.

Mi entrada de lleno al barrio la hice el 11 de enero del 2014 por medio de un proyecto llamado: "Patios productivos" organizado por la ONG Granitos de Paz, la cual está localizada en cercanías de La Villa. Dicho proyecto nació con el objetivo de generar ingresos económicos a la población más pobre del sector a través del cultivo de vegetales y especias (menta, albahaca, lechuga, rúcula) en los patios de sus casas, para estos después ser vendidos a hoteles de la ciudad. Durante dos semanas seguí al líder de este proyecto en sus visitas técnicas a las casas beneficiadas, de esa forma visibilicé mi presencia en La Villa como miembro de la ONG, aspecto que me brindó protección. Después de dos semanas como voluntario renuncié a la ONG cuando percibí que su trabajo de intervención social estaba viciado de mercantilismo y burocracia, además de mostrar poco interés en la principal problemática social del barrio: los jóvenes, la violencia interpersonal y los enfrentamientos entre pandillas. No obstante, ese tiempo de trabajo produjo un efecto bola de nieve que me llevaron a conocer a varios interlocutores, los cuales uno a uno me fueron introduciendo en la cultura callejera de La Villa en tres personajes claves para el desarrollo de mi investigación: un líder comunitario (Álvaro), un pastor cristiano (Martín) y un ex militar líder (John) de una organización de seguridad barrial llamada Cívica.

\section{Ensamblando el problema, ¿de una tierra de paz hacia un nuevo escenario de violencia urbana?}

La Villa es un lugar complejo en el que actualmente se está configurando un tipo de violencia que es alterno al tradicional conflicto político/armado colombiano y sus actores hegemónicos. La violencia urbana que se presenta 
en las periferias de esta ciudad caribeña al parecer se distancia de lo que ha sucedido en otras capitales colombianas, como la famosa violencia urbana que se vivió en Medellín o Cali durante los años 90 desatada principalmente por carteles del narcotráfico. Incluso, también de la guerra interna que ha existido entre grupos armados ilegales como las guerrillas de las FARC-EP, el ELN (ejército de liberación nacional), grupos paramilitares (especialmente las Autodefensas Unidas de Colombia) y el Estado que durante la década de los 90 y 2000 tuvieron sus mayores picos de incursiones armadas, de atentados y enfrentamientos entre sí o contra las poblaciones que estuvieran en medio de estos actores durante sus enfrentamientos armados.

Las ciudades del Caribe colombiano como es el caso de Cartagena, no ha tenido una relación cercana con las manifestaciones de violencia: ni sus bases sociales, políticas y armadas que la han configurado y dado forma, en contraste con ciudades y territorios al interior del país, reconocidas por esta configuración socio-estructural. Esta distancia con la violencia en todas sus manifestaciones ha creado durante décadas el equivocado imaginario que el Caribe colombiano es "tierra de paz", imaginario que ha funcionado como uno de los principales motivos de migración hacia esta ciudad por parte de población campesina y rural de los departamentos que conforman la región Caribe en las últimas tres décadas (según han afirmado algunos de mis interlocutores más antiguos de La Villa). También el ideal de progreso que representa la ciudad ha contribuido, en la última década, a que los desplazamientos forzados violentos sean la principal razón de esta migración (expulsión). Sin embargo, la emergencia de cientos de pandillas en los barrios periféricos de la ciudad, describen otra realidad alejada completamente de la paz con la que durante mucho tiempo se ha representado el Caribe.

La emergencia de pandillas en la ciudad lanza una serie de hipótesis sobre su configuración que vinculan factores de: clase, género y étnico/raciales con lo cual entender su ascenso en Cartagena, además de su relación con el ensamblaje del aparato del Estado y la construcción histórica de la ciudadanía. Estas pandillas están concentradas principalmente en los barrios materialmente más pobres de la ciudad, $\mathrm{OH}$ es el más grande de estos (Anexo, Mapa 1) y su población mayoritariamente es afrodescendiente (Anexo, Mapa 2) al igual que los integrantes de las decenas de pandillas que observé en La Villa.

La interseccionalidad de este problema se sustenta en la hipótesis que tanto la pobreza, la segregación socio-espacial y la violencia que se presenta en la ciudad tiene raíces estructurales vinculadas con la construcción his- 
tórica de lo que se puede llamar como un: Estado racial (Goldberg, 2002), el cual a su vez ha producido y reproducido una ciudadanía precaria, especialmente para las minorías, debilitando su acceso al capital económico en relación con las ciudadanías hegemónicas (blanco/mestiza), que en el caso de Cartagena se ha concentrado: social, material y simbólicamente en los espacios con mejores condiciones urbanísticas, proyección financiera, turística e inmobiliaria. Esto es un proceso que viene siendo planificado desde los años 70, creando de este modo las condiciones materiales y políticas para desplazar y segregar paulatinamente a la población afrodescendiente a las periferias de la ciudad, proceso que he definido como: violencia estructural (Galtung, 1969).

Todo lo anterior lo he dicho con el propósito de situar al lector en una problemática compleja donde expongo un panorama político externo a los fines etnográficos de mi investigación, pero que es necesario narrar como parte del continuum histórico que me ha llevado a construir y delimitar mi objeto de pesquisa, el cual se concentra específicamente en describir la emergencia de las pandillas y su violencia local en un escenario global que puede entenderse en términos de Bourdieu como: capital cultural y simbólico heredado, pero que para los fines de mi investigación defino aquí como la: potencialidad de la violencia. Para tal motivo me he planteado las siguientes preguntas $\left.{ }^{2}: 1\right)$ ¿Qué es una pandilla, cómo operan y se articulan en esta periferia urbana y por qué su alto grado de violencia?, y 2) ¿Habrá en esta manifestación de violencia alguna relación con la segregación étni$\mathrm{ca} /$ racial que la población afrodescendiente ha sufrido históricamente en la construcción y consolidación del Estado-Nación moderno?

Sin embargo, cabe anotar que durante el transcurso de mi etnografía descubrí que las pandillas no fueron los únicos actores violentos del barrio. Consecuentemente a su emergencia se constituyó una organización de seguridad interna que tiene como nombre "Cívica", y gran parte de sus miembros son ex-pandilleros y ex-militares. La emergencia de ambos grupos es significativa porque representan un microcosmos similar a las lógicas bélicas de los actores armados tradicionales en Colombia. A continuación resumiré la emergencia de ambos reconstruyendo su ascenso y conformación por medio del relato de algunos de mis interlocutores, principalmente miembros de la Cívica, los cuales devienen tanto de pandillas como de las fuerzas militares.

2 Preguntas que son la base de una investigación de mayor envergadura. 


\section{Las pandillas, "nosotros no hacemos nada, nos la pasamos en la calle"}

Conocer a jóvenes pandilleros no ha sido un trabajo fácil, sólo después de dos meses de intenso trabajo de campo en La Villa pude acercarme a ellos mediante dos ex pandilleros que ahora integran la organización "Cívica". Aunque ellos no estuvieran relacionados directamente con pandillas, era la primera vez que podía escuchar el punto de vista de estos jóvenes sin la mediación, interpelación o interpretación de otras personas ajenas a este proceso. Uno de ellos tiene 33 años, es padre de tres hijos, uno de 14, otro de 8 y uno de 6 años. El otro tiene 26 y es padre de un niño de 4 años. La noche del 10 de febrero de 2015, a modo de justificación lo primero que ellos me dirían cuando les pregunté sobre la violencia en el barrio, será lo siguiente:

Nosotros nos dedicamos sacar la Cívica por las pandillas que hay aquí en la vía perimetral. Del lado de la villa estaban atracando, aquí no podíamos permitir que eso sucediera, entonces la comunidad nos está ayudando de poquito a poquito. Ya de este lado hemos acabado con la guerra que había antes, con la violencia de los robos gracias a dios se ha terminado. La violencia ha sido dura porque cada nada sucedían las peleas, la policía se metía acá y cada nada salían los disparos, gases lacrimógenos. Entonces los que más sufren son los niños. La idea de la Cívica nació de eso, gracias a Dios hemos acabado con los conflictos entre pandillas porque también ellos se metían a robar aquí. Sólo en esta calle hay 7 muertos por robos, en esta misma calle que cuidamos los han matado, por eso queremos seguir así hasta que esa gente ese canse de le pelea (Ricardo, entrevista, 10 febrero 2015).

Esta entrevista se extendería durante una hora, tiempo en el cual estos jóvenes contestarían una a una todas las preguntas, dudas e hipótesis a priori que antes yo consideraba claves para comprender sociológicamente la configuración interna de las pandillas, su discurso, sus prácticas violentas y su cotidianidad, pero después de esta entrevista dichas hipótesis resultaron equivocadas. A partir de este momento, el objeto de mi investigación comenzó a tomar forma manifestando un escenario con unas características únicas y distantes de cualquier interpretación académica conocida antes que pudiera arrojar algún tipo de argumento para explicar la emergencia de las pandillas en las periferias de Cartagena. A continuación expondré las preguntas y las respuestas que considero las más relevantes en esta entrevista. 
Yo: ¿Por qué hay tanta violencia aquí?

Ricardo: Es que los niños pequeños al ver esas peleas (conflicto entre pandillas) ya están con la mentalidad de la pelea y quieren estar en la misma, hay unos chamitos (niños) de 10 años que se hacen llamar los mini Z, ellos se pelean con otros niños del Tancón (Tienda de esquina), y eso lo hacen repitiendo lo que uno hacia antes. Pero ya eso cambió, lo que eran las peleas, los robos, el 100\% lo hemos calmado.

Yo: ¿Cómo ha sido ese proceso?

Ricardo: Ha sido lento pero seguro, con la ayuda de Álvaro nos han entregado unos radios y uniformes para cuidar de esta calle y otras como: la calle San Bernardo, la 19 de abril y La villa. La gente colabora poco, pero las ganas de nosotros no es el dinero sino las ganas de mejorar el barrio, queremos que se acabe la violencia, el robo para que gente de fuera digan que la villa es un lugar sano.

Yo: ¿Ustedes usan armas?

Ricardo: Por ahí tenemos una vainita (revolver) porque el bandido también tiene lo suyo, hay que protegerse, el bandido está aquí mismo, ellos tienen lo suyo (armas) y van echando tiros, por eso nosotros tenemos que recibirlo con lo mismo. Yo: ¿Cómo se forman los enfrentamientos?

Ricardo: Lo de las peleas es que si uno de aquí va para allá ellos se llenan de odio porque piensan que los de aquí les van a quitar a las chicas, entonces ahí viene el rencor, ahí es que se forma que los de allá no cruce para aquí y los de aquí para allá, así es que se forma todo. Cada vez que llueve eso es pelea efectiva (asegurada), las pandillas se encuentran para matarse allá en la perimetral usando cuchillo, revolver, armas caseras, armas raras que se inventan con tubos.

Yo: ¿Cómo funciona y organiza la cívica?

Gabriel: Por ejemplo, salen 6 muchachos diarios en la noche, cada uno de ellos tiene su familia, por eso necesitamos de un recurso, la noche se paga entre 16.000018 .000 mil pesos (20-22 reales). Así es que nosotros sobrevivimos, en la semana podemos ganar 80.000 mil pesos (98 reales), sumado con el trabajo que uno tiene fuera. Nosotros sólo salimos a trabajar los sábados.

Yo: Desde lo que he observado me parece que en el barrio se libra una guerra, ¿por qué se están matando ustedes aquí dentro?

Ricardo: $\mathrm{Si}$, nosotros mismos nos matamos, disque los perros son animales pero uno mismo la disque humanidad somos los animales y nosotros matándonos a nosotros mismos. En este momento Cartagena está llena de pandillas en barrios al sur como El socorro o Blas de Lezo, considerados antes como buenos barrios ahora ya no lo son más, todo eso ahí está lleno de maquias (pandilleros). 
Yo: He pensado que aquí ustedes se estaban peleando el territorio por la venta de drogas, ¿es verdad?

Gabriel: No, aquí no pelean nada, aquí lo que pelean es el territorio de que cada uno se quede en sus lados, los jóvenes se cogen odio detrás del cero. Mucho dicen que pelean por un territorio como se ve en otras ciudades para cuidar de un negocio. ¿Drogas? aquí no, los jóvenes pelean atrás del cero matándose por nada, ¿cuántos muertos no han habido aquí? Muchos, la Cívica es la respuesta a esta violencia porque yo tengo un hijo de 14 años y no quiero que él siga creciendo viendo toda esa violencia. Por lo menos hemos mejorado este sector, no el barrio completo porque el barrio es grandísimo, sino sólo este sector. En el resto hay más pandillas, La Villa antes era la peor calle pero ya la hemos calmado; y sí vamos a tener que meter mano dura lo vamos hacer, "se les da candela" (tiros).

Yo: ¿Cuál es el lugar y el día más peligroso?

Ricardo: Los sábados las pandillas se meten por la perimetral, entonces ha habido varios enfrentamiento porque cada que vez que se vienen aquí ellos ya saben que no se pueden meter aquí. La policía esta alegre con nosotros, lo que ellos no pudieron hacer lo hicimos nosotros, acabamos con la pelea, con los robos. El comandante (de la policía) pasa por aquí y nos felicita, es que los superiores de ellos los pasan regañando cuando hay mucho robo y pelea por aquí, entonces ellos ganan con nuestro trabajo.

Yo: ¿Es verdad que envían helicópteros aquí cuando hay peleas?

Gabriel: ¡Sí!, a veces los helicópteros dan vueltas encima del barrio, pero ya hace rato no los mandan, eso solía suceder cuando aquí antes había mucho conflicto entre las pandillas, el helicóptero venía buscando a alguien con muchas órdenes de captura. Este trabajo es peligroso, ya cuando uno se mete en esto se gana de enemigo a los bandidos, pero también tenemos un poco de militares en la Cívica. (Ricardo y Gabriel, entrevista, 10 febrero 2015)

Antes de dar inicio a mi investigación de campo supuse que la emergencia de las pandillas en Cartagena tenía alguna relación con bandas criminales aliadas al narcotráfico por el hecho de ser una ciudad capital y un puerto importante de exportación de mercancías al exterior, especialmente hacia los Estados Unidos. Pero esta tesis resultó ser falsa porque según la explicación de estos jóvenes el tráfico de drogas no tiene nada que ver con los conflictos por el territorio, sus prácticas delictivas y su violencia. El tráfico de drogas al interior del barrio no representa un mercado de grandes proporciones al cual apropiarse, dado que el consumo de drogas en la ciudad es míni- 
mo en relación a la gran cantidad de drogas que son incautadas y enviadas al exterior por medio del puerto.

Además, las pandillas no tiene el capital económico, la organización, la inteligencia, ni las armas suficientes para competir con las bandas criminales aliadas al narcotráfico y grandes carteles de tráfico de droga que operan desde otras ciudades, pero que a pesar de la distancia tienen oficinas (como si fueran franquicias de empresas) en Cartagena con personal altamente cualificado en el mundo del crimen, que operan en los puertos vigilando las rutas de envío de la droga: de la logística, de los sobornos y del capital humano criminal.

Varios días después de esta entrevista hice un recorrido acompañado por John a alrededor de la zona más conflictiva de La Villa donde los jóvenes suelen reunirse a socializar y fumar marihuana, la droga de mayor consumo. Observé que para las pandillas el tráfico de drogas y la disputa del territorio aparentemente no es una característica propia de su organización. Según sus argumentos, es el estilo de vida que han adaptado a sus condiciones locales, copiado del imaginario de pandillas al estilo Norteamericano mediante el consumo visual, con lo cual afirmar haber construido una identidad. Cuando le pregunté a este grupo de pandilleros con una edad promedio de entre 14 a 25 años sobre, ¿qué hace una pandilla en La Villa?, uno de ellos respondió:

Hacemos lo que hace una pandilla: ocio, perder tiempo, la fiesta, las chicas, el picó (evento de música popular): todos van al picó, toda pandilla se encuentra ahí, y siempre el objetivo es el de tener las peladas (chicas). (Pandillero, entrevista, 13 febrero 2015).

Luego les pregunté lo siguiente, ¿qué es lo que ustedes hacen como pandilla? El líder de este grupo respondió y el resto concordó con él:

Nosotros no hacemos nada, nos la pasamos en la calle, unos pasan robando por ahí o fumando marihuana, yo solo fumo marihuana, pero esos de allá le jalan al perico (cocaína), la mayoría solo fumamos, pero no mucho (Pandillero, entrevista, 13 febrero 2015).

El tema de las drogas para el desarrollo de mi investigación es una variable importante, porque es un hecho que transversaliza la mayor parte del material bibliográfico existente sobre violencia urbana en Colombia. No obstante el caso de Cartagena representa un nuevo paradigma de investigación, debido a que sí el mercado de drogas no es un recurso importante para la expansión y emergencia de las pandillas, entonces ¿qué es lo que produ- 
ce la emergencia de esta violencia? Existe un vacío de interpretación que necesita ser llenado por medio de datos etnográficos, con lo cual se pueda describir, por ejemplo; las razones por las cuáles los jóvenes expresan de sí mismos: "nosotros no hacemos nada, nos la pasamos en la calle".

¿Por qué estos jóvenes no hacen nada?, ¿por qué la calle se convierte en su principal actividad? Estas son dos preguntas que me interesó responder para determinar cuáles y qué tipo de relaciones sociales establecen estos jóvenes entre su esfera privada y pública, es decir, describir lo que sucede en la mediación de ambas esferas porque el hecho de ellos "no hacer nada" manifiesta un nivel de ausencia y desigualdad de oportunidades a la cual estos jóvenes no pueden acceder en lo público como en lo privado. Ausencia/vacío que se puede entender como los efectos directos de la violencia estructural.

Eso quiere decir que cuando un joven dentro de una pandilla responde que: "la vida de uno es esto, estar en la pandilla, en eso termina nuestra vida, las peleas, la vaina (los problemas), esperar morir en esto porque no hay más para hacer, así es la vida aquí", se convierte en una afirmación preocupante que describe precarias condiciones de vida que están produciendo generaciones de jóvenes sin ningún futuro, pero sobre todo, la aceptación de la muerte como destino en sus vidas, porque como mencionó Gabriel: "los jóvenes pelean detrás del cero matándose por nada".

La totalidad de los interlocutores que conocí en mi trabajo de campo están de acuerdo que para los pandilleros "la vida no vale nada", y este sentimiento trágico queda perfectamente descrito en la frase de Ricardo: "nosotros mismos nos matamos, pensamos que los perros son los animales pero uno mismo la disque humanidad somos los animales".

La existencia de la Cívica ha sido un cambio no solo en lo que se refiere a la seguridad territorial de La Villa, sino que también ha ayudado a muchos de estos jóvenes a modificar sus expectativas de morir en un pandilla, para tener otro proyecto de vida donde nuevas generaciones tengan la posibilidad de vivir en un territorio libre de violencia, y donde además el valor de lo que significa ser humano sea recuperado, tal y como expresó Ricardo cuando dijo que, no quiere que su hijo de 14 años repita su historia.

Sin embargo, en este deseo de cambio, la vida y la muerte siguen jugando un papel importante porque la violencia no termina con la desaparición de las pandillas. Con el tiempo, la Cívica proporcionará aún más violencia 
que la producida por los enfrentamientos entre pandillas, debido a su afán por retomar el control del territorio.

\section{John y la Cívica, el mundo de la periferia}

La casa de John está ubicada en un rincón de la plaza. Pero no es cualquier casa, su interior contrasta con la pobreza material alrededor, sus acabados al interior no tiene nada que envidiar con las casas de la clases media en la ciudad. Casa Al entrar a su casa se puede ver una cámara de video sobre la puerta principal. En la sala hay un televisor, un computador, una impresora, un equipo de sonido, todos estos electrodomésticos de última generación y los acabados en su casa son de lujo. Ahí me encontré con Ricardo y Gabriel, a quienes conocí en la casa de Álvaro. John para sentirse más cómodo puso su pistola calibre 38 (la cual estaba envuelta en una toalla) sobre la mesa. Los demás chicos manejaban efectivo en sus manos, ellos estaban sacando cuentas. Después entró otro joven al que Ricardo le pagó una cantidad considerable de dinero que era para dividir con otra persona, una suma considerable de dinero. Después Gabriel tuvo que irse porque lo estaban esperando en la casa. Al terminar la reunión salimos al frente de su casa para ver a los niños jugar, John llevaba el revólver, todo con el ánimo de infundir respeto, pero sobre todo, estar precavido (15/02/2015 Diario de campo).

Después de tres meses de intensa observación participante, finalmente pude entrar al mundo de la violencia urbana cuando conocí a John en La Vi1la. No obstante, aún en este punto de mi etnografía no tuve un contacto directo con pandilleros, pero la proximidad que me ofreció hacer parte de la Cívica fue suficiente para tener un punto de referencia para acceder a este complejo espacio social y urbano.

John es el líder máximo de la Cívica y como otros de sus miembros, también fue militar. Se pensionó del ejército después de haber sido herido en combate en un enfrentamiento contra las FARC-EP en el año 2010. Volvió al barrio en 2011 donde compró una casa, tiene tres hijos y vive en la zona más peligrosa de La Villa. A finales del año 2014 al frente de su casa hubo un enfrentamiento entre pandillas, hubo disparos con escopeta y varias de esas balas se incrustaron en su puerta y quebraron los vidrios de las ventanas. A partir de ese suceso John tomó la decisión de organizar y liderar la Cívica para detener ese tipo de agresiones armadas. El 15 de febrero 
del 2015 me entrevisté con John, en la misma reunión también estuvieron Ricardo y Gabriel.

Yo: ¿Qué pasa aquí en La villa?

John: Inicialmente esto era una fumadera de marihuana, fumaban en toda la plazoleta, pero los vecinos no eran ajenos a convivir con la fumadera de marihuana y las peleas, parece que toleran todo. Uno a veces cree que eso no le incumbe a uno, pero resulta que un día yo me fui a trabajar como de costumbre cuando me llama mi esposa y me dice que pegaron un tiro en la puerta. Estaban haciendo tiros y ella cerró la puerta, tenemos una bebe pequeñita, una de niña de 7 años y un niño de 5. Cuando ella se entra a la casa el tiro pega en la puerta y parte los vidrios. Entonces yo con Ricardo y Gabriel nos sentamos a hablar y pensamos en armar una cívica, ya existía una vigilancia arriba (en el barrio) pero ellos sólo vigilan arriba. Entonces armamos la Cívica, eso fue algo que se planeó así en vista de las peleas y enfrentamientos. Siempre salíamos los mismos a la calle a bajar los enfrentamientos porque se venían los de allá de otra calle, los del otro lado y uno aquí en el medio. Cada uno tiene sus hijos. Como tú ves ahora los niños están jugando en la plaza, ahí están mis hijos (John, entrevista, 15 febrero 2015).

Y continúa:

¿Cómo es posible que estando en este barrio con un paisaje natural increíble nuestros hijos no puedan jugar ahí (espacio público)? ¿¡Sólo porque tres o cuatro que pelean y el resto (vecinos) no sale a detener eso sino salen sólo a mirar!? De ahí nace la vigilancia. Entonces los señores (Ricardo y Gabriel) se tomaron la molestia de salir a buscar pidiendo firmas de casa en casa a pesar de que ellos pudieron dejar ese problema así. Nosotros no podemos decir a la gente que colabore con un servicio cuando la gente que vive aquí (en el barrio) no tiene los mimos problemas (que La Villa), sólo son los de aquí abajo que convivimos con este problema. Se recolectaron las firmas hablando con la gente, la gente firmó, hubieron algunos que no estuvieron de acuerdo, otros si, los que no estaban antes ahora se han ido metiendo porque ven que esto no es un juego, esto es un hecho. Se tocaron puertas para comprar chalecos para vigilar... Trabajamos con la uñas (John, entrevista, 15 febrero 2015).

Para John la justificación de la Cívica es simple; él quiere proteger a su familia y a la familia de sus amigos, pero también exige hacer uso del espacio público. Por otro lado, esta justificación también evidencia la forma en que la violencia entre pandillas es recibida pasivamente por parte de la co- 
munidad cuando él afirma que: "el resto (de vecinos) no salen a detener eso (los enfrentamientos), sino salen sólo a mirar".

El hecho de que la comunidad no reaccione antes los actos violentos y el consumo de drogas frente a sus casas puede interpretarse desde tres perspectivas. La primera: miedo o terror de las represalias por porte de estos jóvenes, la segunda: una admiración (placer) cultural por la violencia, y la tercera: una aceptación y convivencia resignada con la violencia. Por tanto, en este proceso de resignación y aceptación de la violencia como característica cotidiana en la comunidad, la emergencia de la Cívica representa una agencia con lo cual se rompe la pasiva participación de la comunidad para detener los enfrentamientos entre pandilla, canalizando este apoyo en la aceptación de un uso particular o monopolio de la violencia en manos de la Cívica.

Este proceso de aceptación necesitaría varios meses para ser reconocido en la comunidad como una acción colectiva positiva, porque según John, la situación violenta en La Villa y nuestra organización: "no es un juego, esto es un hecho". Estos hechos a los que se refiere John se irán confirmando con la pacificación del barrio y el nuevo acceso al espacio público que había perdido la comunidad durante el lapso de tiempo en que la Cívica dio inicio a su labor de vigilancia hasta el presente, por ejemplo:

Ricardo: Antes nadie se atrevía salir en la noche por el miedo de que lo atracaran, ahora ya la gente sale, no hay miedo.

John: Sale una persona a las 2 o 3 de la mañana y nuestro deber es llevarlo hasta la avenida, acompañarlo (Ricardo, entrevista, 15 febrero 2015).

John y los demás se sienten muy orgullosos de su trabajo, poco a poco han conseguido el apoyo de líderes comunitarios y políticos locales que les han proporcionado uniformes y radios de comunicación, además de la confianza que poco a poco han conseguido por parte de la comunidad a partir de los resultados a corto plazo en la reducción de peleas, robos, enfrentamientos entre pandillas y percepción de seguridad en el espacio público. Este proceso motivará a la Cívica a mirar más allá y establecer otros objetivos tal como los que señala John:

Ya hemos ido mejorando en cuanto es la peleadera, hay que mejorar otras cosas, pero para eso necesitamos la ayuda de la policía, erradicar por completo las peleas y el vicio (consumo de drogas) de todo el barrio, esa es la meta, eso es posible, pero eso no lo podemos hacer nosotros solos, necesitamos la 
ayuda de muchos, solo llevamos 3 meses y hemos mejorado, ahora imagina sí tuviéramos el apoyo de la parte administrativa, la indumentaria, la infraestructura, se logra (John, entrevista, 15 febrero 2015).

Sin embargo, para él la Cívica no representa sólo una solución a corto plazo para mejorar la seguridad en La Villa, la organización se ha convertido en una alternativa de trabajo, y es precisamente de esa forma que se proyecta a largo plazo el impacto de la Cívica entre los jóvenes de la Villa, sobre esto John mencionará lo siguiente:

Esto genera empleo, que como usted vio esa plata que tenemos aquí es para pagarle a los muchachos. Es dinero que recogemos todos los domingos, las casas dan de 2000 a 3000 mil pesos, con eso le pagamos a la gente (John, entrevista, 15 febrero 2015).

Durante este primer encuentro con él, sobre la mesa de su sala había una cantidad considerable de dinero resultado del pago que los vecinos semanalmente aportan por su servicio de seguridad, pero para él ese dinero es la poca ganancia debido a que tuvieron que invertir en compra de armas. Armas y municiones que en su mayoría vienen del mercado negro.

John define la Cívica como una empresa, y es así como él quiere concientizar al resto de jóvenes que hacen parte de la misma para diferenciarse de otros grupos que prestan este tipo de seguridad en el barrio, de igual forma pretender inculcar en los jóvenes una ética militar con un proyecto familiar, laboral y social de largo alcance.

Después de terminar la entrevista con él en su casa, salimos junto con Ricardo a dar un recorrido por el lugar donde frecuentan las pandillas de La Villa. En aquel momento varios jóvenes pandilleros se acercaron a saludar y a conversar relatando sus últimas experiencias violentas. Estos relatos describen finalmente un escenario social fuera de toda realidad, información periodística o conocimiento académico que se puede tener de La Villa y el barrio $\mathrm{OH}$. Lo que se vive día a día en las periferias marginales de Cartagena no son simples enfrentamientos esporádicos entre pandillas por el control de territorios, sino el ascenso de un nuevo tipo de guerra que se vivirá en Colombia pos-acuerdos de paz. El siguiente diálogo describe este escenario:

Pandillero: Mira, esos pelaos (jóvenes) de allá una vez se metieron aquí (SRN), a un primo le tiraron tres tiros y le partieron los huesos de la pierna. Esos manes de ahí tenían un 38 (pistola) y pasan echando plomo (tiro). Pero 
ellos para acá no cogen porque nosotros les hacemos la guerra, vamos con la misma. A mí no me han herido pero sí me han tirado varias veces con tiros de escopeta. Y esos manes del otro lado tienen más escopetas que revólveres, son escopetas hechizos (artesanales), pero los de aquel otro lado sí tienen revólveres y hay que estar pendiente de ellos porque desde la otra calle también echan tiros (Pandillero, entrevista, 15 febrero 2015).

A partir del anterior relato John agrega y explica cómo la Cívica hace frente a esta violencia a través de una lógica de guerra:

Nosotros cuidamos de ciertas calles y para el otro lado no nos podemos meter porque allá hay otras bandas que están armados también, por eso si uno quiere tomar el control de esos lados hay que llegar echando tiro, no preguntando nada sino matando e invadiendo para que la gente vea que nosotros no estamos hablando mierda, esto es muy serio (John, entrevista, 15 febrero 2015).

\section{La potencialidad de la violencia y otra perspectiva de análisis para entender la periferia}

En esta etnografía se manifiestan nuevos problemas de abordaje teórico y empírico aún sin estudiar en la sociología colombiana contemporánea. Es poca la bibliografía especializada en pandillas en contraste con la abundante bibliografía que se refiere a la historia de la violencia en Colombia ${ }^{3}$. No obstante, el material bibliográfico sobre violencia representa una paradoja sobre la forma en la que yo pretendo abordar la emergencia de pandillas y su

3 Para simplificar esta abundante cantidad de información voy a establecer tres momentos que considero son claves y paradigmáticos en estos estudios sobre violencia. Dichos momentos nacen de comisiones nacionales impartidas por el Estado en los momentos donde el conflicto entre partidos políticos: movimientos sociales de izquierda guerrillera, paramilitares y las FARC-EP llegaron a tal extremo de violencia en sus respectivos periodos de tiempo, que los tratados, amnistías y negociaciones de paz han emergido como única posibilidad de reconciliación. Por lo tanto, los momentos a lo que hago referencia sinterizan largos periodos y gran cantidad de estudios sobre este tema. El primer momento parte del clásico estudio de Orlando Fals Borda, Germán Guzmán y Eduardo Umaña titulado La violencia en Colombia (tomos I y II), publicado en 1962. El segundo momento se resume en el libro Colombia: violencia y democracia de 1987 con la coordinación de Gonzalo Sánchez Gómez. Y el tercer momento nace en 2009 con la apertura del Centro Nacional de la Memoria, lugar en el cual se está recopilando todo lo que tiene que ver con el conflicto histórico, la guerra interna arma y la vulneración de derechos humanos, todo esto con el fin de tener instrumentos para teóricos, pedagógicos y metodológicos para superar la violencia en un periodo (2014-2015) que el Estado está dialogando con las FARC-EP, para conseguir acuerdos y alcanzar la paz. 
violencia en ciudades como Cartagena. Es por ello que primero debo resolver la paradoja que representa los estudios de la violencia de forma general, para luego establecer una ruta de análisis relacionada con el contexto local, al cual definiré como conocimiento situado.

Este conocimiento situado hace referencia a particularidades propias de un contexto social: un tipo de cultura, de economía política, de geografía o condiciones étnicas. Es un universo de significados y configuraciones sociales propias que se diferencian de otros contextos sociales, pero que siendo aun exponencialmente diferentes; continúan manteniendo relaciones de dependencia de lo micro con lo macro. El tipo de violencia que se presenta al interior del barrio $\mathrm{OH}$ es en su mayoría asociado a conflictos entre pandillas. El índice de robos es alto y las principales víctimas están dentro de la comunidad y en los alrededores de este.

Es una violencia física que busca principalmente acabar con la vida de otros mediante enfrentamientos con armas blancas (piedras, cuchillo) y armas de fuego como revólveres y escopetas. Esta expresión de violencia se manifiesta a lo largo y ancho de todo el barrio intensificándose en algunos sectores más que en otros. Las disputas entre estos sectores se han construido a partir de fronteras simbólicas y espacios territoriales en disputa y defensa de estas asociaciones colectivas denominadas pandillas. Pero dichas fronteras necesariamente no son geográficas, ni obedecen a las divisiones político-administrativas del gobierno local el cual sectoriza el barrio. Las pandillas crean nuevas fronteras, ellos pelean por una calle, por una cuadra o por el control de la totalidad de un sector.

Esta manifestación de violencia física representa la paradoja a la que hice mención anteriormente. Según mi etnografía, no existen motivos económicos, criminales o ilegales que incentiven este tipo de violencia como sí suele suceder en otras ciudades colombianas ${ }^{4}$. De hecho, para mis interlocutores el argumento que explica la existencia de las pandillas es que los jóvenes: "no tienen más nada para hacer". Mediante mi observación participante y las entrevistas pude corroborar esta afirmación, en el barrio no existe un tráfico de drogas a gran escala, existe consumo de marihuana y cocaína, pero es en una escala menor siendo los jóvenes entre 15 a 30 años quienes con mayor frecuencia las consumen. Tampoco están ligados a carteles de

4 Véase el libro: Violencia urbana en la región. Radiografia de una región (2014). 
droga. Su principal acción delictiva son los robos y asaltos en los alrededores del barrio y la ciudad.

Por tanto, si el narcotráfico, el crimen organizado y la economía ilegal no constituyen los principales motivos para la articulación de estas pandillas, me pregunto: ¿cuáles son las razones que motivan esta emergencia? En la literatura sobre violencia y estudios urbanos en Colombia, no hay forma de encontrar argumentos que expliquen esta emergencia de grupos y acciones violentas en el Caribe colombiano. La tradición y producción de estas investigaciones han centrado su análisis en ciertos territorios nacionales, lo que dificulta la interpretación y comprensión de otros contextos, sujetos, grupos o instituciones co-re-productores de violencia diferente a los mismos que han constituido históricamente lo que en Colombia se conoce como: violentología 5 .

La violentología se ha centrado principalmente en establecer los orígenes del conflicto armado y político del país desde la década de los años 50 hasta la década de los 90. Los principales actores que estos estudios analizaron fueron la violencia desencadenada por la disputa del control sobre el Estado entre los partidos políticos más antiguos del país: Liberales y Conservadores. Partidos que libraron una guerra sangrienta en las ciudades capitales del interior del país y sus zonas rurales. También estos estudios se especializaron en la emergencia de las FARC-EP y todos los movimientos guerrilleros de izquierda que se enfrentaron ideológica y militarmente contra el Estado y sus fuerzas armadas, buscando apropiarse del poder hasta principios de la década de los 90.

Actualmente (2015-2016) el Estado colombiano está negociando un acuerdo de paz, en este proceso se ha retomado los principales estudios sobre la violencia realizados conjuntamente por las principales universidades públicas y el gobierno nacional para producir una investigación final que compile las principales tesis que expliquen el conflicto armado en Colombia, proponiendo alternativas de desarrollo pensando una sociedad en pos-conflicto.

Este texto, intitulado: Contribución al entendimiento del conflicto armado en Colombia ${ }^{6}$ ha sido el producto de una comisión de investigadores establecida conjuntamente por el Gobierno colombiano y las FAERC-EP,

5 Para un entendimiento resumido de esa propuesta y su trayectoria, véase el libro de Stephen Ferry: Violentology: A Manual of The Colombian Conflict.

6 Este libro aún no ha sido publicado en físico. He tenido acceso a una versión preliminar que está en revisión editorial gracias a un colega que trabaja en el Centro Nacional de la Memoria. Se estima sea publicado a finales del 2015 o inicios del 2016. 
que a la par de otro conjunto de investigación del Centro Nacional de la Memoria $^{7}$, compilan todo lo referido sobre la violencia política, armada y económica desde una perspectiva interdisciplinar de los últimos cincuenta años, además de incluir y ampliar estas contribuciones desde diversas regiones que han sido afectadas por la violencia: pueblos, ciudades, comunidades étnicas, movimientos sociales, líderes sindicales, defensores de derechos humanos, grupos LGBTIQ, en todo el territorio nacional.

Este análisis sobre la violencia se ha concentrado principalmente en dos actores: partidos políticos y movimientos guerrilleros, los cuales hasta inicios de los años 90 constituyeron el objeto de estudio de los violentólogos. Pero desde mediados esa década hasta el 2005, otros actores políticos entraron a escena ampliando la complejidad de la violencia en Colombia, estos son: organizaciones ilegales y criminales ligadas al narcotráfico y grupos paramilitares de ultra derecha (principalmente las Autodefensas Unidas de Colombia (AUC).

Las actuales negociaciones de paz entre el Gobierno colombiano y las FARC-EP representan el desgaste de la guerra y una salida viable de la misma, junto con el desvanecimiento de los grandes carteles del narcotráfico predominante en la década de los 80 y parte de los 90, además del paramilitarismo como institución legítima con su “desmovilización” en el año 2006. Estos actores son los que durante décadas han contribuido a configurar un discurso público y académico sobre la violencia contemporánea en Colombia; invisivilizando otras manifestaciones reales de la misma como las que he observado en La Villa.

En el caso del Caribe, la violencia política/armada de grupos insurgentes de izquierda o derecha o/y la guerra entre carteles del narcotráfico, no tuvieron un impacto directo, a diferencia de: Cali o Medellín, ciudades que en los años 90 sí tuvieron un aumento exponencial en sus tasas de homicidios llegando a ser consideras las más violentas del mundo. Pero indirectamente esta violencia ocasionó el desplazamiento de cientos de miles de personas del campo, hacia las periferias pobres y marginales de ciudades del Caribe colombiano como Cartagena, Barranquilla y Santa Marta.

La configuración sociocultural de esta región del país representa una esfera histórica y estructural completamente diferente al resto del país. Es una región con un ensamblaje social y emergencias propias sobre el uso y formas de violencia poco estudiadas en Colombia, debido a que difieren del

7 Véase el link: www.centrodememoriahistorica.gov. 
modelo hegemónico de interpretación mencionado anteriormente. Para mi investigación es importante establecer esta diferencia, distancia y distinción, porque para entender las formas y usos de la violencia entre pandillas, debe situarse desde lo general hacia lo particular el punto de partida. Por lo tanto, mi propuesta epistemológica es pensar y delimitar lo que representa la violencia en las periferias de Cartagena; a partir de una perspectiva de análisis que yo denomino como: pos-violencia política/armada.

Con esta delimitación quiero centrarme en el entendimiento de la violencia local como una manifestación particular, que con base en los datos recolectados en mi trabajo de campo, confirmo una diferencia radical en contraste al escenario nacional y las investigaciones sobre sociología de la violencia urbana desarrollados en Colombia ${ }^{8}$. Es por ello que la violencia que ejercen las pandillas en Cartagena y la propia emergencia de estas, representan otra paradoja porque a pesar de existir una bibliografía extensa en Latinoamérica sobre estos grupos, etnográficamente son limitados los estudios que exploran desde dentro de las pandillas: su producción social, configuración, emergencia y formas de violencia.

La ausencia de investigaciones sobre violencia urbana y pandillas $^{9}$ no sólo es preocupante por la importancia del tema, sino porque sustenta la hipótesis que planteada aquí al respecto de que en el Caribe colombiano, hay otra configuración social, cultural y territorial desligada de las dinámicas violentas presentes en el resto del país. Dinámicas que por ejemplo, obligaron a decenas de mis interlocutores a tomar la decisión de migrar a Cartagena por considerar a la ciudad: un "territorio de paz" en tiempos de guerra nacional, no obstante lo hicieran en sus periferias marginales.

8 Los artículos que citaré a continuación hacen un compilado general e histórico de la bibliografía, la pedagogía y las principales temáticas de investigación urbana y sociología urbana desarrollados en el país. Desarrollo histórico y perspectivas de la investigación urbana en Colombia 1960-1992 de Orlando Sáenz Zapata (1993). El Estudio de la ciudad en los programa académicos de sociología de la universidad nacional de Colombia (1959-2004), de Franz Guzmán Gámez y José Luis Ortiz Hoyos (2005). La enseñanza de la sociología urbana en la universidad nacional (1975-2005), de Rocío Londoño (2009).

9 Las investigaciones que los autores señalan existen en Colombia sobre pandillas fueron realizadas principalmente por Carlos Mario Perea (2007) en su libro: Con el diablo adentro. Pandillas tiempo paralelo y poder. Ese trabajo se realizó en tres ciudades capitales: Barranquilla, Bogotá y Neiva. $\mathrm{Su}$ principal objetivo es analizar comparativamente la emergencia de pandillas en estas ciudades estudiando sus particularidades, semejanzas o diferencias, además de dialogar con la literatura sobre pandillas de Centro América como punto de comparación. 
Sumando estas condiciones y al efecto devastador de la violencia estructural sobre poblaciones étnicas minoritarias y sin ciudadanía plena de derechos, las periferias se convirtieron en un espacio de recepción no solo de migrantes víctima de violencia, sino un ejército social excedente, marginal y subalterno como la población afrodescendiente la cual mayoritariamente habita en la ciudad, relegada a estos territorios urbanos desprovisto de servicios públicos básicos con condiciones materiales de: habitat, espacio público y presencia del Estado, sumamente precarizados.

Estas características estructurales sumadas a la pobreza económica y su relegación histórica, ha contribuido a condensar en el barrio $\mathrm{OH}$ una serie de características socio-espaciales únicas que posibilita encadenar el desarrollo La Villa en relación directa, con el legado elitista blanco del ejercicio del poder político en la ciudad y el Estado, produciendo así; una división étnico/ racial jerárquica del espacio urbano, la sociedad y su derechos ciudadanos, lo que Wacquant (2007) describe como un tipo de cerrazón social y relegación espacial en perspectiva estructural. Aspecto que potencializa y explica la emergencia de pandillas juveniles: su economía ilegal y criminal.

\section{Palabras finales}

Desafortunadamente aún es pronto para tener conclusiones finales en este artículo, lo que he presentado aquí es solo un avance preliminar de un problema teórico y conceptual, que conforme avanza el desarrollo de mi investigación empírica ha ido tomando forma, con lo cual he podido establecer una ruta epistemológica situando una problemática local co-relacionada estructuralmente con un escenario nacional. Los datos etnográficos aún son limitados porque la dificultad de entrar en contacto con las pandillas en el barrio ha sido difícil y mucho más ha sido el ganarme su confianza. No obstante, espero concluir esta etnografía a finales del 2016 porque el proyecto de investigación está planeado terminarse a mediados del 2018. Por lo tanto, en este punto de mi investigación es poco lo que puedo proponer para descifrar las razones por las cuales han emergido las pandillas a lo largo y ancho de las periferias urbanas de Cartagena, y las razones que motivan sus formas de sociabilización violenta, criminales e ilegales en el Caribe colombiano. 


\section{Bibliografía}

Ferry, S. (2012). A manual of the colombian conflict. New York: Umbrage Editions, Inc.

Galtung, J. (1969). Violence, Peace, and Peace Research. Journal of Peace Research 6, 167-191.

Goldberg, D. (2002). The Racial State. Malden: Blackwell Publishers INC.

Guzmán G., F., \& Ortiz H., J. (2009). El estudio de la ciudad en los programas académicos del Departamento de Sociología de la Universidad Nacional de Colombia (1959 - 2004). En: P. Quintin Q. (Comp.), La sociología en Colombia. Balance y perspectiva. Cali: Editorial Universidad del Valle.

Guzmán, G., Fals Borda, O. \& Umaña, E. (2005). [1962, 1963]. La violencia en Colombia (tomos I y II). Bogotá: Taurus.

Londoño, R. (2009). La enseñanza de la sociología urbana en la Universidad Nacional (1975-2005). En: P. Quintin Q. (Comp.), La sociología en Colombia. Balance y perspectiva. Cali: Programa Editorial Universidad del Valle.

Sánchez, G. (2009). Comisión de Estudios sobre la Violencia, Colombia: violencia y democracia. Medellín: La Carreta.

Sánchez, L. (2003). Barranquilla: Lecturas urbanas. Cartagena: Observatorio del Caribe.

Violencia urbana (2014). Radiografía de una región. Aguilar: Bogotá.

Wacquant, L. (2007). Los condenados de la ciudad. Gueto, periferia y Estado. Buenos Aires: Siglo XXI Editores.

\section{Entrevistas}

Joven 1, Febrero 2015

John, Febrero 2015

Pandillero, Febrero 2015 


\section{Anexos}

\section{Mapa 1 \\ Porcentaje de personas de ingresso bajo Cartagena ${ }^{10}$}

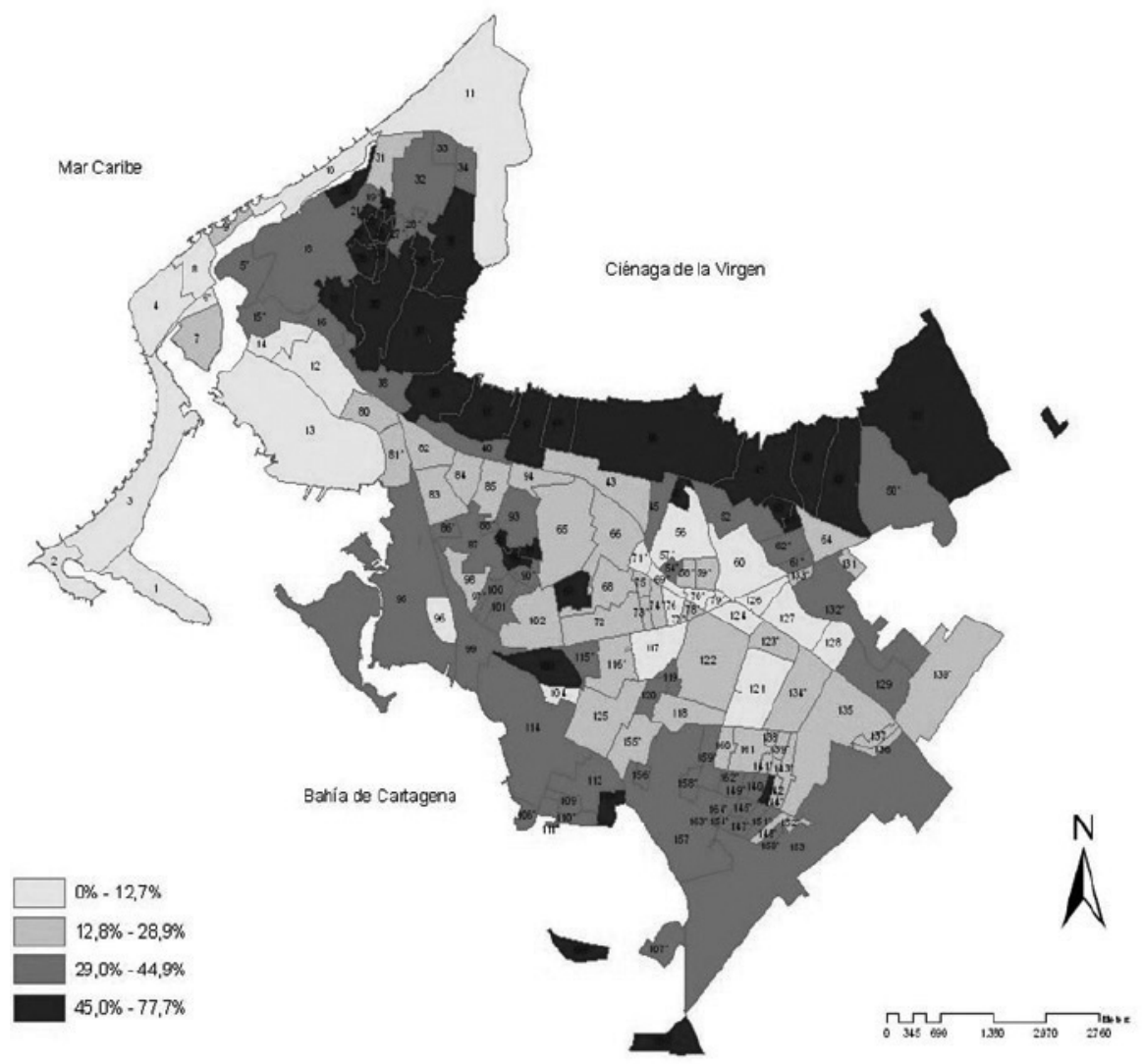

Fuente y elaboración: Banco de la República (Colombia)

10 Como se observa en esta imagem, los ingresos más bajos se concentran en la localidad De La Virgen y turística, localidad que en su mayoría está constituída por el barrio Olaya Herrera. 


\section{Mapa 2 \\ Porcentaje de habitantes afrodescendentes en los barrios de Cartagena}



Fuente y elaboración: Banco de la República (Colombia)

Fecha de recepción: 2016-12-08; fecha de aprobación: 2016-12-26 
